\title{
A New Technique for Analysis of Static Eccentricity in Axial Flux Resolver
}

\author{
F. Tootoonchian ${ }^{1}$, K. Abbaszadeh ${ }^{2}$ and M. Ardebili ${ }^{3}$ \\ ${ }^{1}$ Ph.D. Candidate of Electrical and Computer Engineering, K. N. Toosi University of Technology, Shariati street, 16314, \\ Tehran, Iran, Tootoonchian@iust.ac.ir \\ ${ }^{2,3}$ Electrical and Computer Engineering, K. N. Toosi University of Technology, Shariati street, 16314, Tehran, Iran, \\ Abbaszadeh@eetd.kntu.ac.ir, Ardebili@eetd.kntu.ac.ir
}

\begin{abstract}
Resolvers have been widely used in motion control systems as position sensors. This paper deals with the analysis of Axial Flux Resolvers. Axial flux resolvers are a group of resolvers which can be used in high performance servomechanisms. The accuracy of resolver detected position is affected by errors. Some of these errors are caused by speed fluctuations, permeance ripples, unbalanced voltages, and eccentricity between rotor and stator. Among these errors the static eccentricity (SE) is not corrected electronically. In this paper, the eccentric resolver is modeled analytically based on d-q synchronous rotating coordinate system with different $L_{d}$ and $L_{q}$ values and then, the static eccentricity effect based on the developed model is studied. A novel algorithm is proposed for suppressing the eccentricity error. This method is based on analytical model and modern control fundamentals. In a comparison, simulation and experimental results show good agreement. Finally, the effect of air gap length, pole number and excitation voltage on position error of eccentric AFR is investigated, practically.
\end{abstract}

Keywords: Position sensor, axial flux resolver, static eccentricity, dynamic model, state feedback, pole placement

\section{INTRODUCTION}

$\mathrm{T}^{\mathrm{s}}$ HE ACCURACY and resolution of the absolute rotor position signal have a major effect on the performance of motion control systems. The most famous absolute position sensors are resolvers and optical absolute encoders [1-3]. Comparing with optical absolute encoders, resolvers are more mechanically reliable and can easily be integrated with motor systems [4]. Furthermore, they have robust structure and a wide range of operation temperature [4]. Resolvers are of two types: A) radial flux resolvers (conventional) and B) axial flux resolvers (AFR). The second one has some advantages over conventional resolvers. For example, it has a short axial length. So, it is useful wherever limited axial length is available. Beside this advantage the machines with axial flux structure have another major preference. The influence of static eccentricity (SE) which is an inevitable error in the bearings of the rotary machines is reduced in axial flux structure [5-6]. Since the SE has a major effect on the resolver output signals, it needs a major consideration and it is essential to reduce $\mathrm{SE}$ effect as much as possible.

It is to be noted that the eccentricity can be regrouped into: static eccentricity (SE) and dynamic eccentricity (DE). In the case of SE, the rotor rotates around its own geometric axis which is not the geometric axis of the stator. In case of $\mathrm{DE}$, the rotor is not concentric and rotates around the geometric axis of the stator [5]. As reported in [5-6], an inherent level of SE exists even in newly manufactured machines due to the build-up of tolerances during manufacturing and assembly procedure. Thus, in this paper the effect of static eccentricity on the resolvers is investigated.

Some of the important factors affecting the resolver errors obtained from previous works [1-4, 7-9] are summarized as:
1) spatial harmonics in the output voltage; 2) magnetic designs; 3) coil installations; 4) bearing wear; and 5) manufacture and assembly tolerance. Although, using an analytic method for permeance harmonics based on slot combinations and winding arrangements has been proposed in [4], the application of such a method has been difficult to implement in practice. Ref. [8] describes a magnetic field analysis method to obtain an optimal magnetic design which eliminates harmonics using 2D FEM (two-dimensional finite element method). However, it is a time consuming process and its authors themselves have mentioned that their method is not practical and not accurate enough. In [9] it was shown how the short-circuit winding of a resolver reduces the angular error due to the rotor eccentricity.

Furthermore, there are lots of works on improving the accuracy of resolver to digital converters which has been reported in [10-13]. The dynamic and steady state performance analysis of resolvers has been presented in [14] with the effect of eccentricity and stator current neglected.

The dynamic behavior of the resolver can be described by a set of nonlinear differential equations. These equations may be linearized for small perturbations about an operation point. The objective of this paper is to present a mathematical model based on $\mathrm{d}-\mathrm{q}$ axis theory to predict the dynamic and static behavior of the brushless resolver, considering eccentricity effect and a new compensation method based on state feedback and pole placement theory. The proposed method has some advantages, such as simplicity, accuracy and time saving. Another preference of the proposed method is its ability to diagnose eccentricity using the variation of Eigenvalues.

Finally, simulation results are compared with experimental AFR signals and good agreement between them shows the algorithm ability. 


\section{AXIAl FluX Resolver MOdel}

The following assumptions are considered in the analysis:

a) Stator has distributed two phase windings.

b) Rotor has a winding with sinusoidal supply.

c) The effect of static eccentricity in the AFR is taken into account.

d) The effect of stator currents is considered.

Fig.1 shows the schematic of axial flux brushless resolver and its d-q model. As shown in Fig.1.(a), the axial flux brushless resolver has a single stator and single rotor configuration with an axial flux rotary transformer. Rotary transformer transfers the exciting signal without any brushes. Furthermore, each stator winding flux consists of leakage flux and main flux. The latter flux is linked to the rotor. The mathematical model of AFR can be described in linear and nonlinear differential equations.

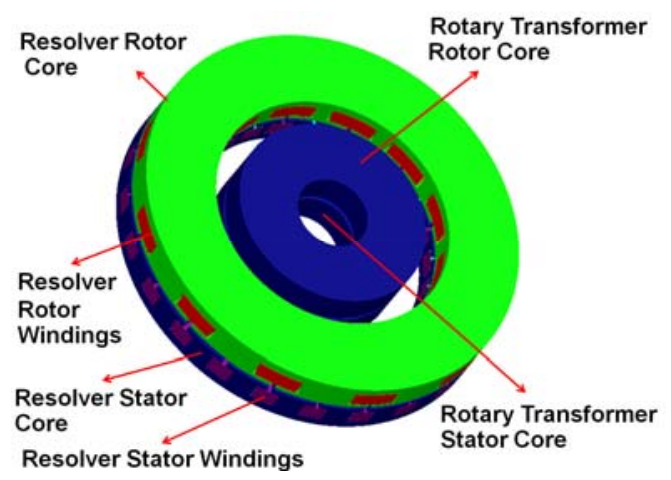

(a)

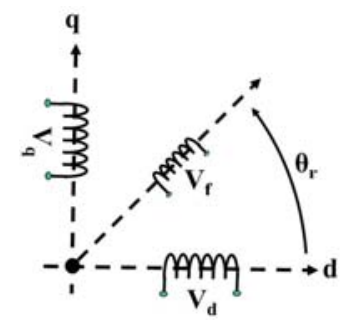

(b)

Fig.1. (a) the structure of axial flux brushless resolver, (b) d-q model of resolver

\section{A. Nonlinear MODEL}

The voltage equations in machine variables may be expressed as:

$$
\begin{aligned}
V_{r}= & r_{r} i_{r}+L_{r r} \frac{d i_{r}}{d t}+\omega_{r} L_{s r} \cos \theta_{r} i_{a s}+L_{s r} \sin \theta_{r} \frac{d i_{a s}}{d t} \\
& +\omega L_{s r} \sin \theta_{r} i_{b s}-L_{s r} \cos \theta_{r} \frac{d i_{b s}}{d t} \\
= & v_{r}^{\prime} \cos \left(\omega_{f} t+\psi\right) \\
V_{a s}= & -r_{s} i_{a s}+2 \omega_{r} L_{m s} \sin 2 \theta_{r} i_{a s}+L_{m s} \sin 2 \theta_{r} \frac{d i_{b s}}{d t} \\
& -2 \omega_{r} L_{m s} \cos 2 \theta_{r} i_{b s}-L_{s r} \sin \theta_{r} \frac{d i_{r}}{d t} \\
& +\omega_{r} L_{s r} \cos \theta_{r} i_{r}+(\overbrace{L_{\ell s}+L_{0}-L_{m s} \cos 2 \theta_{r}}^{L_{s}}) \frac{d i_{a s}}{d t}
\end{aligned}
$$

$$
\begin{aligned}
V_{b s} & =-r_{s} i_{b s}-2 \omega_{r} L_{m s} \cos 2 \theta_{r} i_{a s}-L_{m s} \sin 2 \theta_{r} \frac{d i_{a s}}{d t} \\
& -2 \omega_{r} L_{m s} \sin 2 \theta_{r} i_{b s}+\omega_{r} L_{s r} \sin \theta_{r} i_{r} \\
& +(\overbrace{L_{\ell s}+L_{0}+L_{m s} \cos 2 \theta_{r}}^{L_{s}^{\prime}}) \frac{d i_{b s}}{d t}-L_{s r} \cos \theta_{r} \frac{d i_{r}}{d t}
\end{aligned}
$$

Symbol definitions are presented in the Appendix.

The stator variables are transferred to the rotor reference frame which eliminates the time-varying inductances in the voltage equations and all rotor variables refer to the stator windings by appropriate turn ratios. Park's equations are obtained by setting the speed of the stator frame equal to the rotor speed. The voltage-current equations are as follows:

$$
\left[\begin{array}{c}
V_{q s} \\
V_{d s} \\
V_{r}^{\prime}
\end{array}\right]=\left[\begin{array}{ccc}
-r_{s}+\frac{p}{\omega_{b}} X_{q s} & \frac{\omega_{r}}{\omega_{b}} X_{d s} & \frac{\omega_{r}}{\omega_{b}} X_{m d} \\
-\frac{\omega_{r}}{\omega_{b}} X_{q s} & -r_{s}+\frac{p}{\omega_{b}} X_{d s} & \frac{p}{\omega_{b}} X_{m d} \\
0 & \frac{p}{\omega_{b}} X_{m d} & r_{r}^{\prime}+\frac{p}{\omega_{b}} X_{r r}^{\prime}
\end{array}\right] \times\left[\begin{array}{c}
i_{q s} \\
i_{d s} \\
i_{r}^{\prime}
\end{array}\right]
$$

Where:

$$
\begin{array}{ll}
X_{q s}=X_{\ell s}+X_{m q} & , X_{m q}=X_{0}-X_{m s} \\
X_{d s}=X_{\ell s}+X_{m d} & , X_{m d}=X_{0}+X_{m s}
\end{array}
$$

The electromagnetic torque developed in the resolver is given by:

$$
T_{e m}=\frac{P}{2 \omega_{b}}\left(\psi_{d} i_{q}-\psi_{q} i_{d}\right)
$$

And the mechanical equation of resolver in per-unit can be written as:

$$
T_{\text {mech }}(p u)-T_{e m}(p u)-T_{\text {damp }}(p u)=2 H \frac{d\left(\omega_{r} / \omega_{b}\right)}{d t}
$$

Based on (1)-(4) the electrical equivalent circuit of the AFR is presented in Fig.2. Table I shows the parameters of the equivalent circuit. The electrical parameters of AFR can be calculated by using the DC-Pulse method [15].

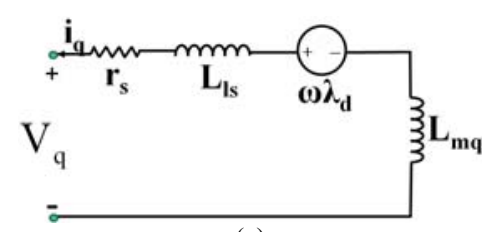

(a)

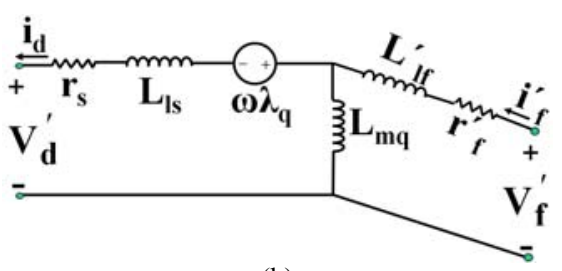

(b)

Fig.2. Electrical equivalent circuits of axial flux resolver, (a) q-axis equivalent circuit, (b) d-axis equivalent circuit 
Table 1. The Equivalent Circuit Parameters of Tested Axial Flux Resolver

\begin{tabular}{|c|c|c|}
\hline Parameter & Unit & Value \\
\hline $\mathrm{r}_{\mathrm{s}}$ & $\Omega$ & 29 \\
\hline $\mathrm{r}_{\mathrm{f}}^{\prime}$ & $\Omega$ & 17 \\
\hline $\mathrm{L}_{\mathrm{m}}$ & $\mathrm{H}$ & $3.41 \times 10^{-3}$ \\
\hline $\mathrm{L}_{\mathrm{lf}}^{\prime}$ & $\mathrm{H}$ & $0.11 \times 10^{-3}$ \\
\hline $\mathrm{L}_{\mathrm{ls}}$ & $\mathrm{H}$ & $0.11 \times 10^{-3}$ \\
\hline $\mathrm{J}$ & $\mathrm{kg} \cdot \mathrm{m}^{2}$ & $9.13 \times 10^{-4}$ \\
\hline
\end{tabular}

\section{B. LINEAR MODEL}

The methods of linearization are divided into two categories: 1) analytic perturbing methods and 2) software based methods. In the former, the nonlinear differential equations are perturbed around the operating point and in the latter, some functions of SIMULIK/MATLAB software are employed [16]. In the software based method, the simulation block diagram of AFR is plotted in Simulink. Then, the "LINMOD" function of Matlab is used to obtain the system's linear models of ordinary differential equations (Odes). Finally "TRIM" function is employed to find steady state parameters for the Simulink system.

Both linearization methods were used. Comparison between their results indicated that both of them had an acceptable accuracy. Finally, the method of linearization used in this research leads to the following linear timeinvariant system of equations:

$$
\begin{aligned}
& \dot{X}=A X+B U \\
& Y=C X+D U
\end{aligned}
$$

Equation (8) can be rewritten as below (using small perturbation around the operating point):

$$
\begin{aligned}
& \dot{\Delta} X=A \Delta X+B \Delta U \\
& \Delta Y=C \Delta X+D \Delta U
\end{aligned}
$$

Where:

$$
\begin{aligned}
& \Delta X=\left[\Delta \psi_{q s}, \Delta \psi_{d s}, \Delta \psi_{r}^{\prime}, \frac{\Delta \omega_{r}}{\omega_{b}}, \Delta \theta_{r}\right]^{t} \\
& \Delta U=\left[\Delta V_{q s}, \Delta V_{d s}, \Delta T_{\text {mech }}\right]^{t} \\
& \Delta Y=\left[\Delta \theta_{r}\right]^{t}
\end{aligned}
$$

The numerical coefficients of (8) can be calculated by using average DC pulse response of stator current [17]. By assuming $L_{d}=L_{q}$, the Eigenvalues of symmetrical resolver are:

$$
|\lambda I-A|=0 \Rightarrow\left\{\begin{array}{l}
\lambda_{1}=-234.16 \\
\lambda_{2,3}=-16.07 \pm 9.11 i \\
\lambda_{4,5}= \pm 0.58 i
\end{array}\right.
$$

To investigate the performance of AFR with static eccentricity, in the above procedures $\mathrm{L}_{\mathrm{d}}$ is assumed to be unequal with $\mathrm{L}_{\mathrm{q}}\left(\mathrm{L}_{\mathrm{d}} \neq \mathrm{L}_{\mathrm{q}}\right)$. Then, the Eigenvalues of AFR considering $10 \%$ eccentricity (about $0.100 \mathrm{~mm}$ ) can be calculated as:

$$
\left|\lambda I-A^{\prime}\right|=0 \Rightarrow\left\{\begin{array}{l}
\lambda_{1}=-59.1 \\
\lambda_{2,3}=-128.6 \pm 21.4 i \\
\lambda_{4,5}= \pm 25.2
\end{array}\right.
$$

\section{RESULTS AND DISCUSSION}

Fig.3 shows the manufactured resolver and its experimental test setup. The experimental resolver was an axial flux resolver with the specifications presented in Table II.

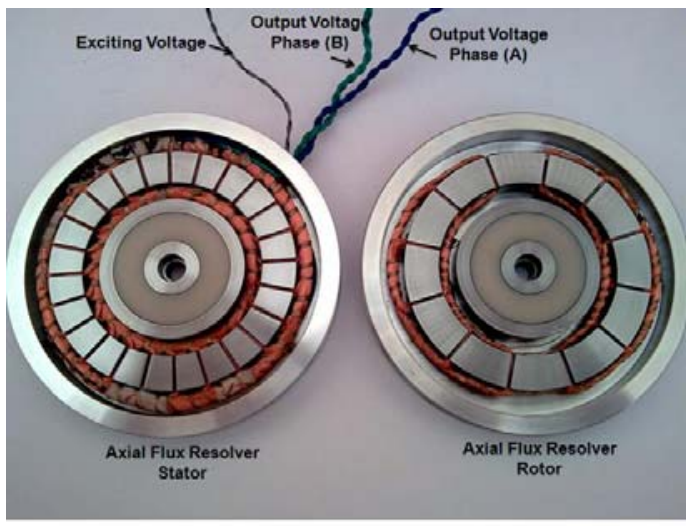

(a)

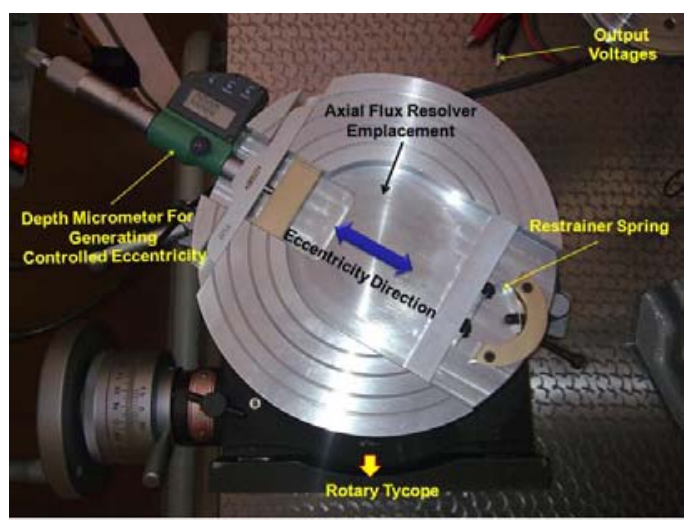

(b)

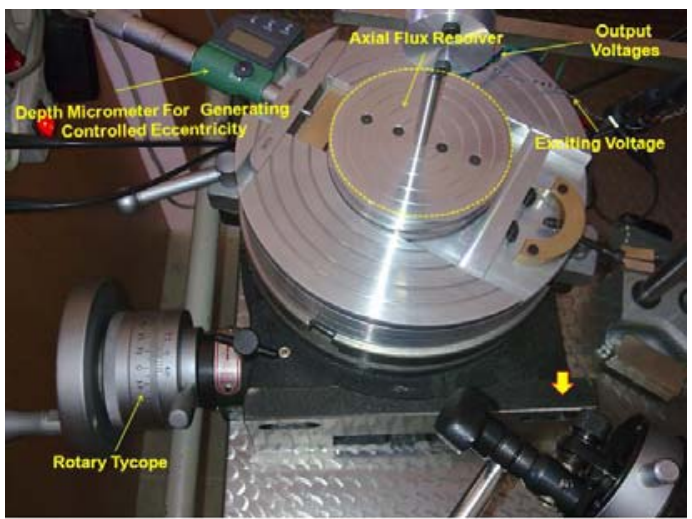

(c)

Fig.3. (a) Axial Flux Resolver (AFR), (b) Experimental measurement setup without AFR, (c) Experimental measurement setup with eccentric AFR 
Table 2. The Specifications of Tested Axial Flux Resolver

\begin{tabular}{|l|c|c|}
\hline \multicolumn{1}{|c|}{ Parameter } & Unit & Value \\
\hline Frequency & $\mathrm{Hz}$ & 4000 \\
\hline Peak to Peak input voltage & $\mathrm{V}$ & 10 \\
\hline Maximum position error & $\mathrm{min}$ & 10 \\
\hline Pole number & - & 2 \\
\hline Maximum speed & $\mathrm{rpm}$ & 8000 \\
\hline Air gap length & $\mathrm{mm}$ & 1 \\
\hline Core outer /inner diameters & $\mathrm{mm}$ & $72 / 52$ \\
\hline Core length, stator/rotor & $\mathrm{mm}$ & $10 / 10$ \\
\hline Duty cycle & & $\mathrm{S}_{1}$ \\
\hline Number of turns, Stator/Rotor & - & $1200 / 600$ \\
\hline
\end{tabular}

It is to be noted that simulation and measured results can be compared in two categories:

(a) Loading test of AFR, because it is similar to a synchronous generator with sinusoidal excitation.

(b) Comparison of position data, since the resolver is a position sensor.

Both of them can be done for symmetrical and eccentric AFR in the same air gap length.

\section{A. AFR as a Synchronous Generator}

Fig.4 shows the practical and computed d-q voltages of resolver with the excitation of about $4000(\mathrm{~Hz})$. As shown, the amplitude of experimental voltages is larger than of the simulation ones. This can be attributed to the capacitor effect of the stator windings neglected in simulation or the errors in parameter identification. To know the exact reason,

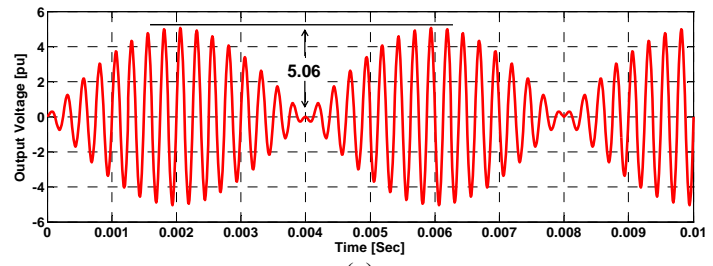

(a)

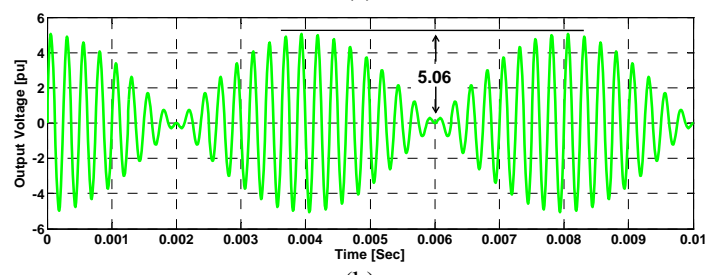

(b)

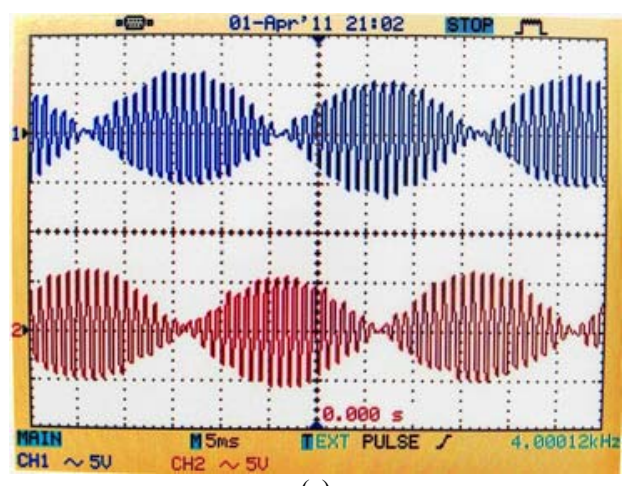

(c)

Fig.4. Output voltage of asymmetrical resolver versus time with $4000 \mathrm{~Hz}$ excitation (a) simulated q-axis voltage (b) simulated daxis voltage and (c) measured $\mathrm{q}-\mathrm{d}$ axis voltage the simulation was repeated with $400 \mathrm{~Hz}$ excitation frequency and its results are presented in Fig.5. Good agreement between these results with the experimental ones confirms that the difference between Figs.4-a,b and 4-c is related to the capacitor effects of the stator windings. Table III and Fig.6 show the summary of simulation and test results. They show good agreement between test and simulation results and validate the resolver model presented in this paper.

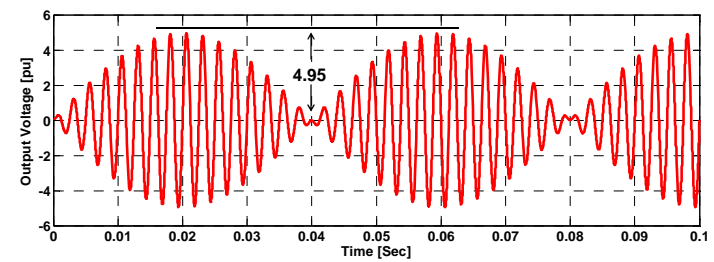

(a)

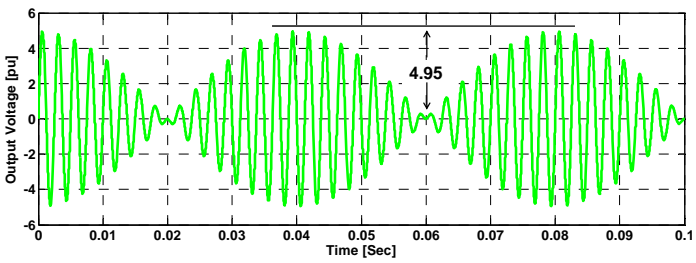

(b)

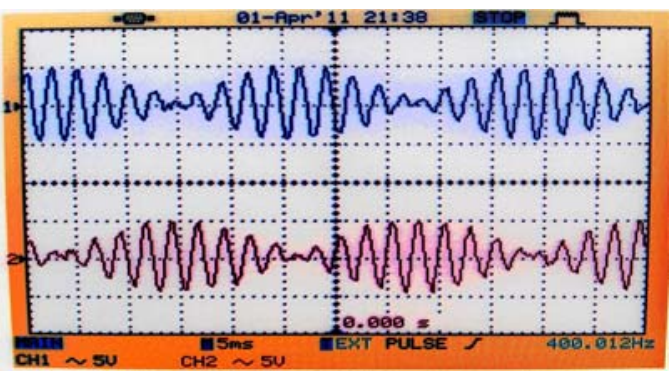

(c)

Fig.5. Output voltage of asymmetrical resolver versus time with $400 \mathrm{~Hz}$ excitation (a) simulated q-axis voltage (b) simulated d-axis voltage and (c) measured $\mathrm{q}-\mathrm{d}$ axis voltage

Table 3. Comparison of Calculated and Measured Results

\begin{tabular}{|c|c|c|c|c|}
\hline $\begin{array}{c}\text { Output current } \\
(\mu \mathrm{A})\end{array}$ & $\begin{array}{c}\text { Frequency } \\
(\mathrm{Hz})\end{array}$ & $\begin{array}{c}\text { Output voltage } \\
(\text { simulated })\end{array}$ & $\begin{array}{c}\text { Output voltage } \\
(\text { measured })\end{array}$ & $\begin{array}{c}\text { Error } \\
(\%)\end{array}$ \\
\hline 60 & 4000 & 5.06 & 5.21 & 2.88 \\
\hline 60 & 400 & 4.95 & 4.89 & -1.23 \\
\hline
\end{tabular}

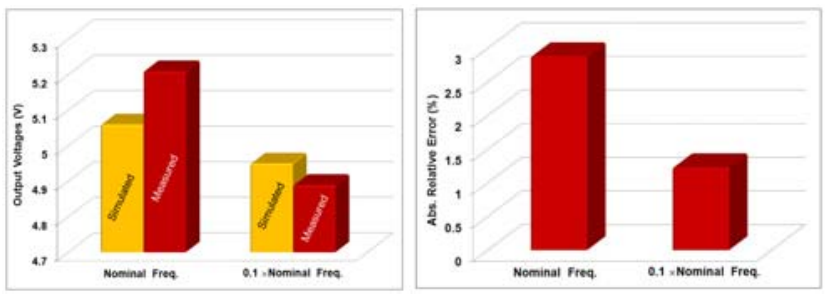

(a)

(b)

Fig.6. Comparisons of calculated and measured results of resolver as electrical machinery (a) output voltage in volt, (b) relative error in per unit 


\section{B. AFR as a Position Sensor}

The main task of axial flux resolver is position sensing. Thus, the accuracy of detected position must be evaluated. To this end, a high precision position sensor (rotary tycope) which is connected to VF5-HP25 CNC (Computer Numeric Control) machine was employed as the reference of position. Furthermore, resolver detected position is calculated considering arctangent of output voltage ratio.

Fig.7 shows the comparison of simulated $\mathrm{d}-\mathrm{q}$ model position error with that of manufactured AFR. This figure confirms that the maximum position error difference between measured and simulated results is 6 Arcmin at 245 degrees. However, the maximum position error of simulated and fabricated AFR versus real position is about 9 and 5 Arcmin (at $300{ }^{\circ}$ and $325^{\circ}$ ), respectively.

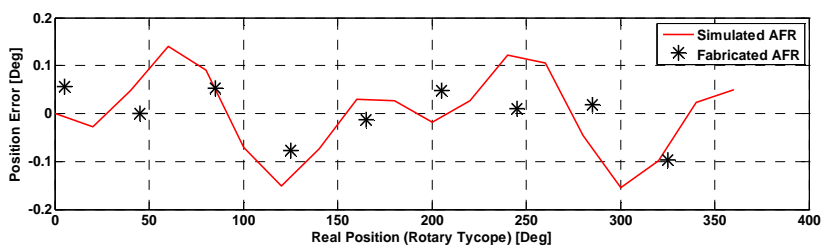

Fig.7. Comparison of calculated angular position with resolver output and high precision position sensor output

\section{AFR with Eccentricity}

\section{C.1. Effect of Eccentricity}

Fig. 8 shows the output voltages of eccentric axial flux resolver. For accurate comparison the output position signals of symmetrical and eccentric resolver are shown in Fig.9. In this figure the AFR detected position is calculated considering arctangent of output voltage ratio.

Fig.9 shows that the rotor eccentricity of $0.100 \mathrm{~mm}(10 \%$ gap eccentricities) causes the error 7.8 Arcdeg in the detected angular position.

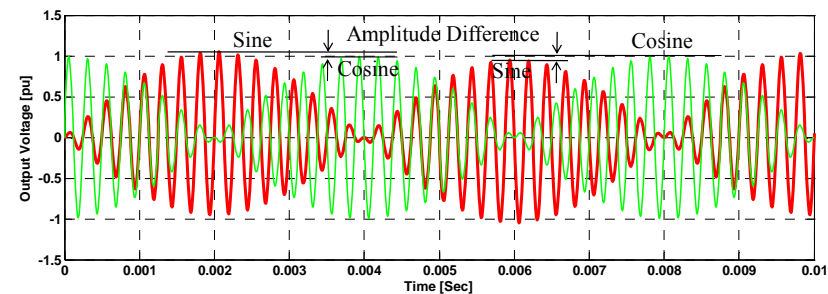

Fig.8. Output voltages of eccentric resolver versus time with $4000 \mathrm{~Hz}$ excitation

As shown in Fig.10, the position error decreases from 7.8 to 1.7 Arcdeg. When the eccentricity increases from 10 to $70 \mu \mathrm{m}$ with a $1 \mathrm{~mm}$ air gap length, it is almost fixed while the eccentricity is more than $70 \mu \mathrm{m}$.

Also, the effect of air gap length, pole number and excitation voltage harmonics on position error was investigated.

Fig.11 shows the dependence of position error of AFR on the real position at $10 \mu \mathrm{m}$ gap eccentricity and different air gap length. The position error decreases when the air gap length increases from $0.4 \mathrm{~mm}$ to $2 \mathrm{~mm}$. Then, the effect of pole number on the position error was studied. The variation of the position error with the pole number at $1 \mathrm{~mm}$ air gap length and $10 \%$ rotor eccentricity is shown in Fig.12. As shown, the position decreases with an increasing pole number. The position error reduction can be attributed to the decrease in overhang leakage flux of stator winding due to the reduction of overhang length caused by the increase in pole number.

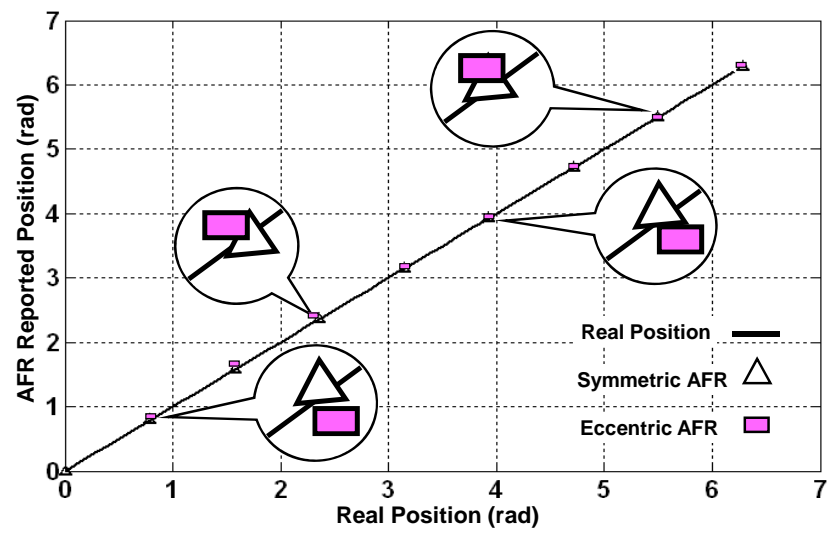

Fig.9. Comparison of angular position in eccentric and symmetrical resolver

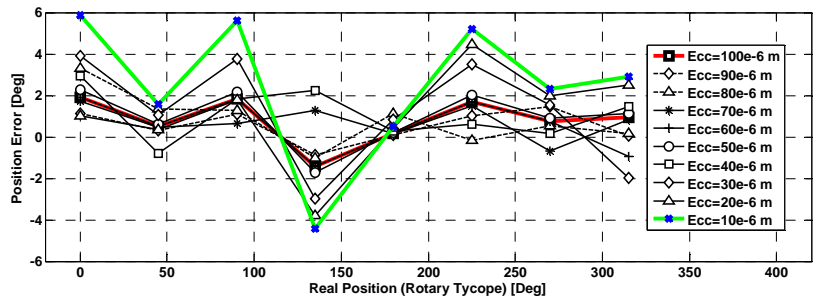

Fig.10. Position error of AFR versus real position with $1 \mathrm{~mm}$ air gap length and different gap eccentricity values

Finally, the effect of excitation voltage harmonics on the position error of AFR with $10 \mu \mathrm{m}$ gap eccentricity and $1 \mathrm{~mm}$ air gap length is perused in Fig.13. In all of the preceding analyses it was assumed that the resolver excitation signal was an ideal cosinusoid and contained no additional harmonics. In general, the excitation signal contains harmonics and thus the AFR output signals in the ideal case are simplified as:

$$
\begin{aligned}
& \left\{\begin{array}{l}
V_{s}=\operatorname{Sin} \theta \sum_{n=1}^{\infty} V_{s n} \operatorname{Cos}(n \omega t) \\
V_{c}=\operatorname{Cos} \theta \sum_{n=1}^{\infty} V_{c n} \operatorname{Cos}(n \omega t)
\end{array}\right. \\
& \Rightarrow \theta=\operatorname{Arctg}(\operatorname{tg} \theta \times \underbrace{\sum_{n=1}^{\infty} V_{s n} \operatorname{Cos}(n \omega t)}_{A} \underbrace{\infty}_{n=1} V_{c n} \operatorname{Cos}(n \omega t)
\end{aligned}
$$


As presented in (12) and Fig.13, AFR position error increases when its excitation current harmonic contents (part A in (12)) increase. For example, when excitation current harmonic contents increase up to $50 \%$, AFR position error increases even up to 15.4 Arcdeg.

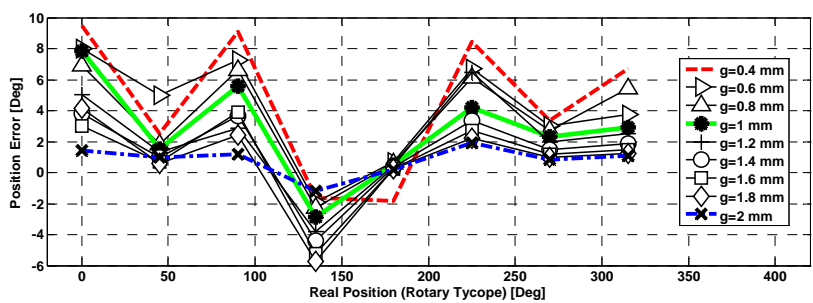

Fig.11. Position error of AFR versus real position in $10 \mu \mathrm{m}$ gap eccentricity and different air gap length

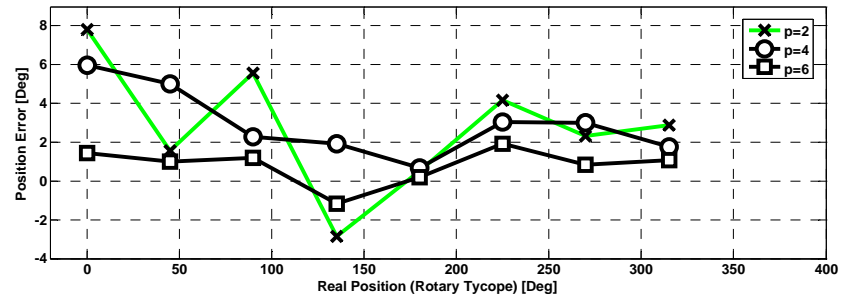

Fig.12. Position error of AFR versus real position in $10 \mu \mathrm{m}$ gap eccentricity and different pole numbers

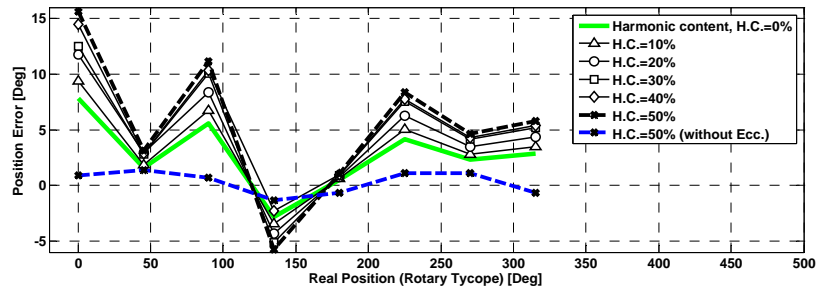

Fig.13. The effect of excitation voltage harmonics on the position error of AFR with $10 \mu \mathrm{m}$ gap eccentricity

\section{C.2. Proposed Compensation Method}

For error elimination, state feedback algorithm is proposed. The controllability and observability of the system were tested in advance and then, the Eigenvalues of eccentric resolver were shifted toward those of the symmetrical one. These symmetrical Eigenvalues are presented in (11) and (12).

The required feedback matrix can be calculated as:

$$
\left\{\begin{array}{l}
\dot{X}(t)=A X(t)+B u(t) \\
u(t)=-K X(t)+u^{\prime}(t)
\end{array} \Rightarrow \dot{X}=[A-B K] X(t)+B u^{\prime}(t)\right.
$$

Where $\mathrm{K}$ is feedback matrix:

$$
\begin{aligned}
& K=\left[\begin{array}{lllll}
141.4359 & -0.5116 & -140.1584 & 2.7255 & 1.519
\end{array}\right. \\
& \begin{array}{rrrrr}
126.3245 & 0.0078 & -0.0113 & 1.441 & 113.719
\end{array} \\
& \left.\begin{array}{llllll}
1.4331 & 0.0001 & -0.0153 & 0.0010 & -0.1413
\end{array}\right]
\end{aligned}
$$

Fig.14 shows the compensated angular position of eccentric AFR using state feedback with that of symmetrical AFR. It is clear that the proposed method has a significant effect on the sensor output, and the position error is restricted to \pm 6 Arcmin.

The other preference of the proposed algorithm is its ability to diagnose eccentricity. In other words, the components of feedback matrix can be used for detection of eccentricity in the AFR or in others.

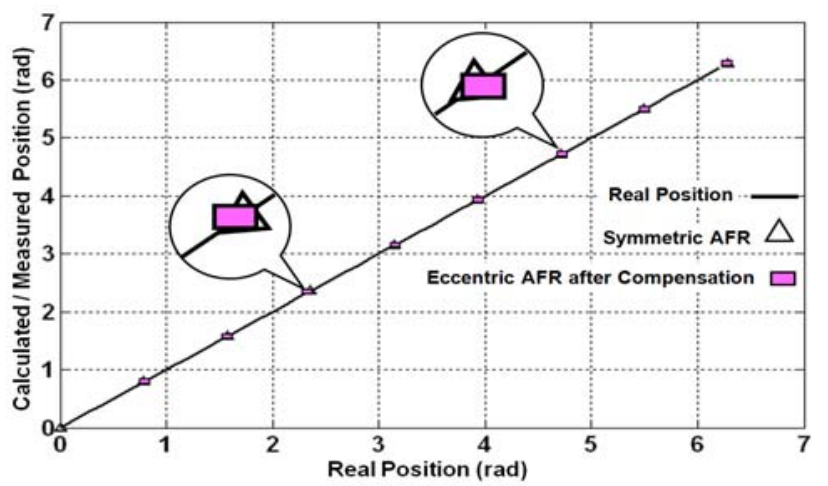

Fig. 14. Comparison of symmetrical and 10\% eccentric AFR output using state feedback

\section{CONCLUSIONS}

Although the main advantage of the axial flux resolver (AFR) over a conventional one is its robustness against static eccentricity (SE), the effect of eccentricity on the accuracy of output signals is also very important. So, in this paper a new dynamic analysis of AFR considering the effect of static eccentricity (In studied $\mathrm{d}$ - $\mathrm{q}$ model $\mathrm{L}_{\mathrm{d}}$ and $\mathrm{L}_{\mathrm{q}}$ are assumed differently) has been presented. Then, the AFR equivalent circuit was presented and its parameters were obtained by using average DC pulse response of its stator current. AFR was simulated with these identified parameters and its simulated dynamic responses were compared with practical results and a good agreement was achieved. Moreover, the Eigenvalues of symmetrical and eccentric AFR were obtained, practically. By using these Eigenvalues a novel method for detection of eccentricity and reduction of its effect based on the state feedback theory has been proposed. Comparing the output of symmetrical AFR with that of compensated eccentric resolver regards the success of the proposed method. Finally, the effect of different SE levels, air gap length, pole number and excitation voltage harmonics on position error of an experimental AFR is investigated, practically. This study showed that the AFR position error is strongly distorted with SE less than $70 \mu \mathrm{m}$. But, it decreases with increase of air gap length and pole number. 


\section{APPENDIX}

List of Symbols

Parameter
A
$\mathrm{B}$
$\mathrm{i}_{\mathrm{as}}, \mathrm{i}_{\mathrm{bs}}$
$\mathrm{i}_{\mathrm{r}}$
$\mathrm{H}$
$\mathrm{K}$
$\mathrm{L}_{\text {fs }}$
$\mathrm{L}_{\mathrm{ms}}$
$\mathrm{L}_{\mathrm{rr}}$
$\mathrm{L}_{\mathrm{sr}}$
$\mathrm{p}$
$\mathrm{P}$
$\mathrm{r}_{\mathrm{r}}$
$\mathrm{r}_{\mathrm{s}}$
$\mathrm{T}_{\mathrm{damp}}$
$\mathrm{T}_{\mathrm{mech}}$
$\mathrm{U}$
$\mathrm{V}_{\mathrm{as}}, \mathrm{V}_{\mathrm{bs}}$
$\mathrm{V}_{\mathrm{r}}$
$X$
$\omega_{\mathrm{r}}$
$\theta_{\mathrm{r}}$
$\mathrm{r}$
$\mathrm{s}$

\section{Definition}

$\mathrm{n} \times \mathrm{n}$ constant matrix

$\mathrm{n} \times \mathrm{m}$ constant matrix

stator currents

rotor current

feedback matrix

The inductance of rotor circuit $\mathrm{d} / \mathrm{dt}$

Pole pairs

The resistance of rotor circuit

the resistance of stator circuit

fractional torque

Load torque

stator voltages

rotor angular frequency

electrical angular displacement inertia constant in second

the leakage inductance of the stator winding

the magnetizing inductance of the stator winding

the mutual inductance between the rotor and stator circuits

m-dimensional input variable vector

the excitation signal of the resolver

n-dimensional state variable vector

subscript which is used whit variables and parameters associated with the rotor circuits

subscript which is used whit variables and parameters

associated with the stator circuits

\section{REFERENCES}

[1] Sun, L. (2008). Analysis and improvement on the structure of variable reluctance resolver. IEEE Trans. Magn., 44 (8), 2002-2008.

[2] Benammar, M., Ben-brahim, L., Alhamadi, M.A. (2005). A high precision resolver-to-dc converter. IEEE Trans. Instrum. Meas., 54 (6), 2289-2296.

[3] Benammar, M., Ben-brahim L., Alhamadi, M.A., AlNaemi, M. (2008). A novel method for estimating the angle from analog co-sinusoidal quadrature signals. Sensor. Actuator. A - Phys., 142 (1), 225-231.

[4] Hanselman, D.C., Thibodeau, R.E., Smith, D.J. (1989). Variable-reluctance resolver design guidelines. In Industrial Electronics Society Conference (IECON '89), 6-10 November 1989. IEEE, Vol. 1, 203-208.

[5] Li, X., Wu, Q., Nandi, S. (2007). Performance analysis of a three-phase induction machine with inclined static eccentricity. IEEE Trans. Ind. Appl., 43 (2), 531-541.

[6] Dorrell, D.G., Thomson, W.T., Roach, S. (1997). Analysis of air-gap flux, current, vibration signals as a function of the combination of static and dynamic airgap eccentricity in 3-phase induction motors. IEEE Trans. Ind. Appl., 33 (1), 24-34.
[7] Masaki, K., Kitazawa, K., Mimura, H., Nirei, M., Tsuchimichi, K., Wakiwaka, H., Yamada, H. (2000). Magnetic field analysis of a resolver with a skewed and eccentric rotor. Sensor. Actuator. A - Phys., 81 (13), 297-300.

[8] Hanselman, D.C. (1991). Techniques for improving resolver-to-digital conversion accuracy. IEEE Trans. Ind. Electron., 38 (6), 501-504.

[9] Masaki, K., Kitazawa, K., Mimura, H., Tsuchimichi, K., Wakiwaka, H., Yamada, H. (1998). Consideration on the angular error due to the shaft eccentricity and the compensation effect by short-circuit winding on a resolver. J. Magn. Soc. Jpn., 22 (4-2), 701-704.

[10] Alhamadi, M., Benammar, M., Ben-brahim, L. (2004). Precise method for linearizing sine and cosine signals in resolvers and quadrature encoder applications. In Industrial Electronics Society : 30th Annual Conference of IEEE (IECON 2004), 2-6 November 2004. IEEE, Vol. 2, 1935-1940.

[11] Bünt, A., Beinek, S. (2004). High-performance speed measurement by suppression of systematic resolver and encoder errors. IEEE Trans. Ind. Electron., 51 (1), 49-53.

[12] Yim, C.H., Ha, I.J., Ko, M.S. (1992). A resolver-todigital conversion method for fast tracking. IEEE Trans. Ind. Electron., 39, 369-378.

[13] Kaul, S.K., Koul, R., Bhat, C.L., Kaul, I.K., Tickoo, A.K. (1997). Use of a 'look-up' table improves the accuracy of a low-cost resolver-based absolute shaft encoder. Meas. Sci. Technol., 8, 329-331.

[14] Jiuqing, W., Xingshan, L., Hong, G. (2001). The analysis and design of high-speed brushless resolver plus R/D converter shaft-angle measurement system. In Electrical Machines and Systems : Fifth International Conference (ICEMS 2001), 18-20 August 2001. IEEE, Vol. 1, 289-292.

[15] Khaburi, D.A., Tootoonchian, F., Nasiri-Gheidari, Z. (2007). Parameter identification of a brushless resolver using charge response of stator current. Iranian Journal of Electrical \& Electronic Engineering, 3 (1\&2), 42-52.

[16] Ong, C.M. (1998). Dynamic Simulation of Electric Machinery Using Matlab/Simulink ( $1^{\text {st }}$ ed.). Prentice Hall, ISBN 0-13-723785-5.

[17] Khaburi, D.A., Tootoonchian, F., Nasiri-Gheidari, Z. (2008). Dynamic performance prediction of brushless resolver. Iranian Journal of Electrical \& Electronic Engineering, 4 (3), 94-103.

Received July 14, 2011. Accepted February 28, 2012. 